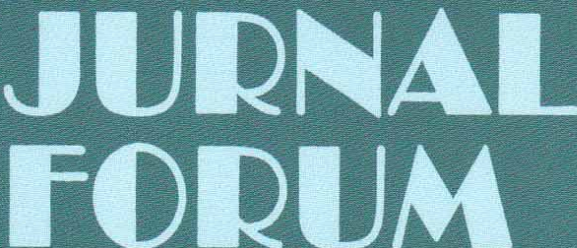

Volume 7 - Nomor 1

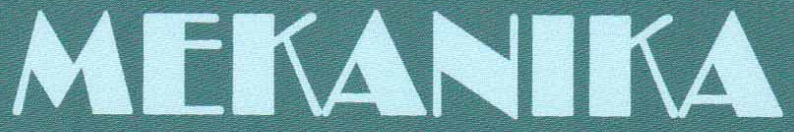

Mei 2018

ISSN : 2356-1491

PENGARUH FLY ASH DENGAN PENAMBAHAN CACAHAN KARET, SILICA FUME DAN SUPERPLASTICIZER TERHADAP BETON

TRI YUHANAH; TOMMY IDUWIN; BUDI WICAKSONO

PERILAKU STRUKTUR TOWER TRANSMISI TIPE SUSPENSION TERHADAP BEBAN ANGIN MUHAMMAD SOFYAN; DICKI DIAN PURNAMA; ABDUL ROKHMAN

IDENTIFIKASI PENYEBAB KECELAKAAN KERJA PADA PROYEK KONSTRUKSI BANGUNAN GEDUNG TINGGI

RETNA KRISTIANA; SLAMET

STUDI SIFAT MEKANIS TANAH MERAH DENGAN PENGUJIAN TRIAKSIAL REFFANDA KURNIAWAN RUSTAM

ANALISIS PENGARUH BESAR BUTIRAN AGREGAT KASAR TERHADAP KUAT TEKAN BETON NORMAL IKA SULIANTI; AMIRUDDIN; RIO SHAPUTRA; DARYOKO

ANALISIS BANJIR DAN TINGGI MUKA AIR PADA RUAS SUNGAI CILIWUNG STA 7+646 S/D STA $15+049$

IKA SARI DAMAYANTHI SEBAYANG; MELIANA PARLINA

ANALISIS KELAYAKAN PERENCANAAN PEMBANGUNAN JALAN PENGHUBUNG (MISSING LINK) ANTARA DESA SIKUR SAMPAI DESA PAOKMOTONG KABUPATEN LOMBOK TIMUR

DESSY ANGGA AFRIANTI; SIGIT IRFANSYAH; MEYRISSA PUTRI DEWANDARI 


\title{
IDENTIFIKASI PENYEBAB KECELAKAAN KERJA PADA PROYEK KONSTRUKSI BANGUNAN GEDUNG TINGGI
}

\author{
RETNA KRISTIANA \\ Program Studi Teknik Sipil, Universitas Mercu Buana, Jakarta \\ E-mail : retna.kristiana@mercubuana.ac.id \\ SLAMET \\ PT. Rekagriya Mitra Buana, Kebayoran Lama, Jakarta Selatan \\ E-mail : slametqs@gmail.com
}

\begin{abstract}
Abstrak
Sumber daya yang paling penting dalam proyek konstruksi adalah tenaga kerja, hal tersebut memungkinkan dapat menimbulkan kesalahan yang dapat mengganggu pelaksanaan. Dengan demikian keselamatan dan kesehatan kerja haruslah selalu dilindungi guna mencegah terjadinya kecelakaan kerja, untuk itu upaya yang dilakukan adalah dengan melakukan evaluasi penyebab kecelakaan kerja pada proyek konstruksi. Dalam tugas akhir ini, permasalahan yang diangkat adalah apa saja indikator dominan penyebab kecelakaan kerja dan bagaimana cara melakukan mitigasi K3terhadap indikator dominan tersebut. Untuk mengetahui indikator dominan tersebut, maka dilakukan observasi dan wawancara dengan personil yang terkait dalam pelaksanaan proyek konstruksi tersebut. Penilaian terhadap indikator dominan ini didapat dengan metode scoring menggunakan skala likert. Dari hasil analisis data pada PT. Pulauintan di proyek Taman Anggrek Residence, Jakarta Barat, secara keseluruhan responden sebanyak 43 orang, responden terbanyak menjawab "setuju" sebesar 67\% dengan 27 indikator penyebab kecelakaan kerja karena kebijakan K3 dalam PP Nomor 5 Tahun 2012 sudah ada, tetapi belum terlaksana dengan baik, dokumentasi belum ada, implementasi K3 belum terlaksana dilapangan. Dan didapatkan indikator dominan adalah dari faktor manusia dengan indikator A.3 sebesar $95.56 \%$ yaitu tingkah laku dan kebiasaan yang ceroboh. Faktor-faktor yang menjadi kendala dalam penerapan kebijakan K3 adalah faktor manusia (SDM), faktor alat-alat kerja, dan faktor kondisi kerja.
\end{abstract}

Kata kunci: Konstruksi, K3, Mitigasi

\begin{abstract}
The most important resource in a construction project is labor, it is possible to cause errors that can disrupt the implementation. Thus the safety and health of the work must always be protected to prevent the occurrence of work accidents, for that effort is done by evaluating the cause of work accidents on construction projects. In this thesis, the issues raised are what are the dominant indicators of causes of occupational accidents and how to mitigate K3 on those dominant indicators. To know the dominant indicator, then do observation and interview with related personnel in the implementation of the construction project. Assessment of dominant indicators is obtained by scoring method using Likert scale. From the results of data analysis at PT. In total, respondents were 43 respondents (67\%) with 27 indicators of occupational accidents due to K3 policy in Government Regulation No. 5 of 2012 already exist, but not yet done well, documentation does not exist, implementation of $K 3$ has not been done in the field. And got the dominant indicator is from human factor with indicator A.3 equal to $95.56 \%$ that is behavior and habit careless. Factors that become obstacles in the implementation of OSH policy are human factor (HR), work tool factor, and working condition factor.
\end{abstract}

Keywords: Construction, K3, Mitigation

\section{Latar Belakang}

Indonesia memiliki undang-undang yang mewajibkan setiap penyedia jasa proyek kontruksi yang berskala besar untuk menerapkan Kesehatan dan Keselamatan Kerja (K3), salah satunya adalah Keputusan Menteri Ketenagakerjaan Republik
Indonesia Nomor : 386 Tahun 2014 tentang Petunjuk Pelaksanaan Bulan Keselamatan dan Kesehatan Kerja Nasional Tahun 2015-2019 menjelaskan bahwa filosofi dasar Keselamatan dan Kesehatan Kerja (K3) adalah menjamin keutuhan dan kesempurnaan melalui perlindungan atas 
keselamatan dan kesehatan para pekerja dalam menjalankan pekerjaannya.

Disadari bahwa pelaksanaan K3 tidak hanya menjadi tanggung jawab Pemerintah, tetapi merupakan tangung jawab semua pihak, khususnya masyarakat industri. Dengan demikian semua pihak terkait berkewajiban untuk berperan aktif sesuai fungsi dan kewenangannya untuk melakukan berbagai upaya dibidang $\mathrm{K} 3$ secara terus menerus dan berkesinambungan serta menjadikan K3 sebagai bagian dari budaya kerja disetiap kegiatan, sehingga dapat mencegah kasus kecelakaan dan penyakit akibat kerja (PAK),(Kepmenaker 386, 2014) ${ }^{1}$.

Banyak perusahaan yang tidak peduli pada keselamatan dan kesehatan kerja para karyawannya, sehingga berakibat pada sering terjadinya kecelakaan kerja dan gangguan kesehatan pada para karyawannya. Apabila terjadi kecelakaan kerja dan gangguan kesehatan pada karyawannya, sesungguhnya yang merugi bukan hanya karyawan itu sendiri dan keluarganya, tetapi perusahaan juga sangat merugi. Perusahaan harus mngeluarkan biaya untuk pengobatan dan memberi santunan, yang mana biaya ini tidak perlu dikeluarkan apabila tidak terjadi kecelakaan kerja atau gangguan kesehatan pada karyawannya (Suparyadi, 2015) ${ }^{2}$.

\section{Landasan Teori}

\subsection{Sistem dan Manajemen}

Dalam buku Imam Soeharto, $1995^{3}$ menjelaskan bahwa sistem merupakan suatu kebulatan atau totalitas yang berfungsi secara utuh, disebabkan adanya saling ketergantungan di antara bagian-bagiannya. Sebagai contoh, suatu organisasi perusahaan yang utuh dan menyeluruh akan terdiri dari bagian-bagian yang saling tergantung baik berupa fisik dan nonfisik. Seperti pimpinan, tenaga pelaksana, keahlian, material, peralatan, dana, logistik, pemasaran, informasi dan lainnya. Sistem juga merupakan Sekelompok komponen yang terdiri dari manusia dan/ atau bukan manusia (nonhuman) yang diorganisir dan diatur sedemikian rupa sehingga komponen-komponen tersebut dapat bertindak sebagai satu kesatuan dalam mencapai tujuan, sasaran bersama atau hasil akhir

Dalam buku Imam Soeharto, $1995^{3}$ menjelaskan bahwa manajemen adalah proses merencanakan, mengorganisir, memimpin, dan mengendalikan kegiatan anggota serta sumber daya yang lain untuk mencapai sasaran organsasi (perusahaan) yang telah ditentukan.

Fungsi manajemen dapat dilihat di gambar 1 dibawah ini :

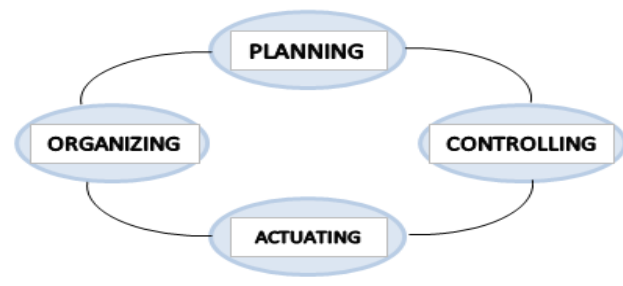

Gambar 1. Diagram fungsi manajemen. Sumber : Iman Soeharto $(1995)^{3}$

Fungsi manajemen menurut pengertian di atas dapat diuraikan lebih lanjut sebagai berikut :

1. Planning/Merencanakan, berarti memilih dan menentukan langkah-langkah kegiatan yang akan datang yang diperlukan untuk mencapai sasaran. Ini berarti langkah pertama adalah menentukan sasaran yang hendak dicapai, kemudian menyusun urutan langkah kegiatan untuk mencapainya.

2. Organizing/Mengorganisir, yaitu segala sesuatu yang berhubungan dengan cara bagaimana mengatur dan mengalokasikan kegiatan serta sumber daya kepada para organisasi agar dapat mecapai sasaran secara efisien.

3. Actuating adalah suatu fungsi kepemimpinan manajer untuk mengarahkan dan mempengaruhi sumber daya manusia dalam organisasi agar mau bekerja secara sukarela untuk mencapai tujuan yang telah digariskan.

4. Controlling/Mengendalikan, yaitu menuntun, memantau, mengkaji dan bila perlu mengadakan koreksi agar hasil kegiatan sesuai dengan yang sudah ditetapkan. Jadi dalam fungsi ini, hasil-hasil pelaksanaan kegiatan selalu diukur dan dibandingkan dengan rencana. Oleh karena itu, umumnya telah dibuat tolak ukur seperti anggaran, standar mutu, jadwal penyelesaian pekerjaan dan lainnya. Bila terjadi penyimpangan, maka akan segera dilakukan pembetulan.

2.2 Sistem Manajemen Keselamatan dan Kesehatan Kerja (SMK3)

1. Menurut Peraturan Menteri Kesehatan No 48 Tahun $2016^{4}$, Sistem Manajemen Keselamatan dan Kesehatan Kerja adalah bagian dari sistem manajemen secara keseluruhan dalam rangka pengendalian risiko yang berkaitan dengan kegiatan kerja guna terciptanya tempat kerja yang aman, efisien dan produktif.

2. Menurut standar OHSAS $18001: 2007^{5}$, SMK3 ialah bagian dari sebuah sistem manajemen organisasi (perusahaan) yang digunakan untuk mengembangkan dan menerapkan Kebijakan K3 dan mengelola resiko K3 organisasi (perusahaan) tersebut.

3. menurut Permen PU No. 05 Tahun $2014^{6}$, SMK3 ialah sistem manajemen organisasi pelaksanaan pekerjaan konstruksi dalam 
rangka pengendalian risiko $\mathrm{K} 3$ pada setiap pekerjaan konstruksi bidang Pekerjaan Umum.

\subsection{Keselamatan dan Kesehatan Kerja (K3)}

1. Dalam PP No. 50 Tahun $2012^{7}$, K3 adalah segala kegiatan untuk menjamin dan melindungi keselamatan dan kesehatan tenaga kerja melalui upaya pencegahan kecelakaan kerja dan penyakit akibat kerja.

2. Menurut keputusan Menteri Tenaga Kerja R.I. No. Kep. 463/MEN/1993 kesehatan dan keselamatan kerja adalah upaya perlindungan yang ditujukan agar tenaga kerja dan orang lainnya di tempat kerja/perusahaan selalu dalam keadaan selamat dan sehat, serta agar setiap sumber produksi dapat digunakan secara aman dan efisien.

3. Menurut Keputusan Menteri Tenaga Kerja R.I. No. Per-01/MEN/I/2007 menjelaskan bahwa Keselamatan dan Kesehatan Kerja (K3) merupakan upaya untuk menciptakan lingkungan kerja yang aman, sehat dan sejahtera, bebas dari kecelakaan, kebakaran, peledakan, pencemaran lingkungan dan penyakit akibat kerja.

\subsection{Keselamatan dan Kesehatan Kerja (K3)}

$\begin{array}{lllll}\text { Dalam PP Nomor } 50 & \text { Tahun } 2012^{7}\end{array}$ menjelaskan bahwa harus ada kebijakan K3 yag dikeluarkan oleh manajemen puncak yang dengan jelas menyatakan seluruh sasaran kesehatan, keselamatan dan komitmen untuk meningkatkan kinerja kesehatan dan keselamatan. Kebijakan tersebut haruslah :

1. Disahkan oleh pucuk pimpinan perusahaan.

2. Tertulis, tertanggal dan ditanda tangani.

3. Secara jelas menyatakan tujuan dan sasaran K3.

4. Dijelaskan dan disebarluaskan kepada seluruh pekerja/buruh, tamu, kontraktor, pemasok, dan pelanggan.

5. Terdokumentasi dan terpelihara dengan baik.

6. Bersifat dinamik.

7. Ditinjau ulang secara berkala untuk menjamin bahwa kebijakan tersebut masih sesuai dengan perubahan yang terjadi dalam perusahaan dan peraturan perundang-undangan

\subsection{Kebijakan Keselamatan dan Kesehatan Kerja (K3)}

Dalam PP Nomor 50 Tahun $2012^{7}$ menjelaskan bahwa harus ada kebijakan K3 yag dikeluarkan oleh manajemen puncak yang dengan jelas menyatakan seluruh sasaran kesehatan, keselamatan dan komitmen untuk meningkatkan kinerja kesehatan dan keselamatan. Kebijakan tersebut haruslah :

1. Disahkan oleh pucuk pimpinan perusahaan.

2. Tertulis, tertanggal dan ditanda tangani.
3. Secara jelas menyatakan tujuan dan sasaran K3.

4. Dijelaskan dan disebarluaskan kepada seluruh pekerja/buruh, tamu, kontraktor, pemasok, dan pelanggan.

5. Terdokumentasi dan terpelihara dengan baik.

6. Bersifat dinamik.

7. Ditinjau ulang secara berkala untuk menjamin bahwa kebijakan tersebut masih sesuai dengan perubahan yang terjadi dalam perusahaan dan peraturan perundang-undangan

\subsection{Syarat-Syarat Keselamatan dan Kesehatan Kerja (K3)}

Menurut UU No. 1 Tahun $1970^{8}$, Bab III Pasal

3 , berikut ini adalah syarat-syarat dari K3 sebagai berikut :

1. Mencegah dan mengurangi kecelakaan.

2. Mencegah dan mengurangi serta memadamkan kebakaran.

3. Mencegah dan mengurangi ledakan.

4. Memberi kesempatan atau menyelamatkan diri dari keadaan bahaya.

5. Memberi pertolongan pertama pada kecelakaan.

6. Memberi alat pelindung diri.

7. Mencegah dan mengendalikan suhu kelembaban, debu kotoran, asap, uap, gas, angin, cuaca, sinar dan suara getaran.

8. Penerangan yang cukup.

9. Memelihara kebersihan dan ketertiban.

10. Memperoleh keserasian antara tenaga kerja, alat kerja, lingkungan, cara dan proses kerjanya.

11. Mengamankan dan memperlancar sistem pengangkutan baik manusia, hewan, tanaman dan barang.

12. Mengamankan segala jenis barang.

13. Mengamankan dan memperlancar pekerjaan bongkar muat dan penyimpanan barang.

14. Mencegah aliran listrik yang berbahaya.

15. Menyesuaikan dan menyempurnakan pengamanan pada pekerjaan yang berbahaya kecelakaan tinggi.

\subsection{Sumber-sumber Kecelakaan Kerja}

Mulyadi, $2015^{9}$ menjelaskan bahwa sumbersumber kecelakaan kerja dipengaruhi oleh beberapa faktor-faktor sebagai berikut :

a. Faktor Manusia (80\%)

1. Pengetahuan dan ketrampilan kurang memadai

2. Fisik kurang baik dan mental labil

3. Tingkah laku dan kebiasaan yang sembrono

4. Sikap pimpinan yang kurang mendukung

b. Faktor Alat-alat Kerja

1. Tidak sesuai dengan postur tubuh

2. Tidak memakai alat pengaman

3. Alat yang ada sudah tidak laik lagi 
4. Meletakkan/menyimpan alat tidak pernah pada tempatnya

5. Alat tidak sesuai dengan apa yang dikerjakan

6. Alat sudah rusak

c. Faktor Kondisi Kerja

1. Mesin, pesawat, alat, instalasi, bahan yang kurang dirawat

2. Lingkungan kerja yang kurang baik

3. Sifat pekerjaan yang monoton

4. Cara kerja yang kurang disiplin

\subsection{Penyebab Kecelakaan Kerja}

1. Tidak terbiasa dengan lingkungan kerja yang tingkat kecelakaannya tinggi

2. Kondisi tempat kerja yang tidak memenuhi persyaratan

3. Lay out/sistim penerangan yang tidak memenuhi persyaratan

4. Cara kerja yang bodoh

5. Mencari kesempatan menggunakan barang/peralatan yang bukan haknya

6. Peralatan yang sudah up to date, tetapi kurang lengkap peralatan yang tersedia

7. Peralatan tidak tersedia untuk melaksanakan pekerjaan

8. Peralatan tersedia tetapi tidak dipergunakan sebagai mana mestinya

9. Kondisi peralatan yang tidak memenuhi persyaratan

10. Terlalu percaya diri, terlalu berani menempuh risiko

11. Tidak menggunakan alat pelindung diri, terlalu berani menempuh risiko, tidak menggunakan alat keselamatan kerja

12. Kondisi fisik pekerja sedang lemah

\subsection{Studi Literatur}

Untuk menyelesaikan masalah yang ada, diperlukan literature untuk mendapatkan landasan teori yang berhubungan dengan permasalahan yang akan diteliti serta digunakan sebagai dasar penyusunan kuesioner. Selain itu, studi literature juga sangat dibutuhkan dalam menentukan metode yang dipakai untuk mengolah dan mengalisis data. Literatur yang digunakan dalam penelitian ini diantaranya sebagai berikut :

1. Kebijakan Keselamatan dan Kesehatan Kerja (K3) dalam PP No. 50 Tahun 2012

2. Syarat-syarat Keselamatan dan Kesehatan Kerja (K3) dalam UU No. 1 Tahun 1970, Bab III Pasal 3

3. Jurnal-jurnal penelitian yang berhubungan dengan penelitian

\section{Metodologi Penelitian}

\subsection{Metode Pengumpulan Data}

Metode pengumpulan data ini langsung dilakukan dengan cara melihat dan melakukan pengamatan secara langsung dan wawancara dilokasi pembangunan proyek Taman Anggrek Residence, Jakarta Barat, untuk mengetahui standar sistem keselamatan dan kesehatan kerja (K3) pada proyek tersebut yang sudah diterapkan dan dilaksanakan kontraktor dalam upaya untuk menekan terjadinya tingkat kecelakaan kerja dan kesehatan pada pekerja dilapangan.

\subsection{Objek Penelitian}

Yang menjadi responden penelitian ini adalah beberapa karywan dan tenaga kerja dalam pembangunan proyek Taman Anggrek Residence, Jakarta Barat.

\subsection{Teknik Analisis Data}

Metode penelitian yang digunakan untuk mengevaluasi penyebab kecelakaan kerja Pada Pembangunan Proyek Konstruksi Bangunan Gedung Tinggi (Studi Kasus : Pembangunan Proyek Taman Anggrek Residence, Jakarta Barat yaitu metode scoring menggunakan metode skala likert yang dikembangkan oleh Rensis likert (1995). Skala likert digunakan untuk mengukur sikap, pendapat, dan persepsi seseorang atau kelompok orang tentang fenomena sosial. Dalam penelitian, fenomena sosial ini telah ditetapkan secara spesifik oleh peneliti, yang selanjutnya disebut sebagai variabel penelitian (Sugiono, 2011) ${ }^{10}$.

\section{Analisis Dan Pembahasan}

Analisis data merupakan merupakan suatu proses pengolahan data yang diperoleh melalui survei (Made Bayu Sambira Teja, 2017).

Hasil penilaian kuesioner dari responden yang telah dibuatkan tabulasi data, selanjutnya dihitung dengan menggunakan rumus sebagai berikut (Bayu, widhiawati, andyana, 2015) ${ }^{11}$ :

Skor $=\frac{\text { Total Skor }(A)}{\text { Nilai Total }(B)} \times 100 \%$

Dimana :

Total Skor $(\mathrm{A})=$ Total Nilai Skor $(1-5)$

Nilai Total $(\mathrm{B})=$ Total Nilai Skor Maksimum

Dalam penelitian ini sistem skor yang digunakan adalah sebagai berikut :

1. Skor 1 STS (Sangat Tidak Setuju) sebagai penyebab utama indikator kecelakaan kerja di proyek pembangunan proyek Taman Anggrek Residence, Jakarta Barat, karena hal sebagai berikut :

a. Diterapkannya kebijakan K3 dalam PP Nomor 5 Tahun 2012

b. Dokumentasi sudah sesuai dengan OHSAS 18001:2007

c. Implementasi K3 sudah sepenuhnya dilaksanakan dilapangan, (diterapkan $100 \%$ ) 
2. Skor 2 TS (Tidak Setuju) sebagai penyebab utama indikator kecelakaan kerja di proyek pembangunan proyek Taman Anggrek Residence, Jakarta Barat, karena hal sebagai berikut :

a. Diterapkannya kebijakan K3 dalam PP Nomor 5 Tahun 2012

b. Dokumentasi ada dan terorganisir dengan baik

c. Implementasi K3 tidak dilakukan secara penuh dilapangan, (diterapkan $\geq 75 \%$ )

3. Skor 3 RG (Ragu-Ragu) sebagai penyebab utama indikator kecelakaan kerja di proyek pembangunan proyek Taman Anggrek Residence, Jakarta Barat, karena hal sebagai berikut :

a. Diterapkannya kebijakan K3 dalam PP Nomor 5 Tahun 2012

b. Dokumentasi ada tetapi tidak terorganisir dengan baik

c. Implementasi K3 tidak dilakukan secara penuh dilapangan, (diterapkan $\geq 50 \%$ )

4. Skor 4 ST (Setuju) sebagai penyebab utama indikator kecelakaan kerja di proyek pembangunan proyek Taman Anggrek Residence, Jakarta Barat, karena hal sebagai berikut :

a. Diterapkannya kebijakan K3 dalam PP Nomor 5 Tahun 2012

b. Dokumentasi belum ada

c. Implementasi K3 belum terlaksana dilapangan

5. Skor 5 SS (Sangat Setuju) sebagai penyebab utama indikator kecelakaan kerja di proyek pembangunan proyek Taman Anggrek Residence, Jakarta Barat, karena hal sebagai berikut :

a. Belum diterapkannya kebijakan K3 dalam PP Nomor 5 Tahun 2012

b. Dokumentasi belum ada

c. Implementasi K3 belum ada

Dari hasil nilai skor yang didapat, maka hasil kesimpulan sebagai berikut :

a. SS : Sangat Setuju diberi skor 5 (Persentase $81 \%$ sampai dengan $100 \%$ )

b. ST : Setuju diberi skor 4 (Persentase $61 \%$ sampai dengan kurang dari $\leq 80 \%)$

c. RG : Ragu-ragu diberi skor 3 (Persentase $41 \%$ sampai dengan kurang dari $\leq 60 \%)$

d. TS : Tidak setuju diberi skor 2 (Persentase $21 \%$ sampai dengan kurang dari $\leq 40 \%$ )

e. STS : Sangat tidak setuju diberi skor 1 (Persentase kurang dari $\leq 20 \%$ )

Analisis perhitungan kuesioner adalah sebagai berikut :

a. Total nilai skor responden 1 terhadap hasil interview 27 pertanyaan :
Tabel 1. Tabel Kuesioner Responden 1

\begin{tabular}{|c|c|c|c|}
\hline Skala likert & Skor & $\begin{array}{c}\text { Jumlah } \\
\text { Pertanyaan }\end{array}$ & Total Skor \\
\hline STS & 1 & 0 & 0 \\
\hline TS & 2 & 0 & 0 \\
\hline RG & 3 & 0 & 0 \\
\hline ST & 4 & 15 & 60 \\
\hline SS & 5 & 12 & 60 \\
\hline Total Skor (A) & & $\mathbf{2 7}$ & $\mathbf{1 2 0}$ \\
\hline
\end{tabular}

Sumber : Olahan Penulis (2017)

b. Nilai Skor Maksimum (B) : 5 x 27 pertanyaan $=135$

c. $\quad$ Skor $=\frac{\text { Total Skor }(A)}{\text { Nilai Total }(B)} \times 100 \%$

Skor $=\frac{120}{135} \times 100 \%$

Skor $=88.89 \%$

Penilaiaan beberapa pertanyaan yang ada di kuesioner menjadi potensi penyebab utama kecelakaan kerja pada responden 1 dalam kategori Sangat Setuju.

\section{Rekapitulasi Kuesioner}

\section{Tim Kontraktor}

Hasil jawaban kuesioner dari tim kontraktor dapat dilihat dari tabel dibawah ini :

Tabel 2. Hasil Jawaban Kuesioner Berdasarkan Kriteria Pertanyaan

\begin{tabular}{|c|c|c|c|}
\hline No & Pertanyaan & $\begin{array}{c}\text { Persentase } \\
(\%)\end{array}$ & Kategori \\
\hline $\mathbf{A}$ & \multicolumn{3}{|c|}{ Faktor Manusia } \\
\hline 1 & $\mathrm{~A} 1$ & 83.33 & Sangat Setuju \\
\hline 2 & A2 & 77.78 & Setuju \\
\hline 3 & A3 & 95.56 & Sangat Setuju \\
\hline 4 & A4 & 82.22 & Sangat Setuju \\
\hline 5 & A5 & 76.67 & Setuju \\
\hline 6 & A6 & 70.00 & Setuju \\
\hline 7 & A7 & 88.89 & Sangat Setuju \\
\hline 8 & A8 & 81.11 & Sangat Setuju \\
\hline 9 & A9 & 78.89 & Setuju \\
\hline B & \multicolumn{3}{|c|}{ Faktor Alat-Alat Kerja } \\
\hline 10 & B1 & 61.11 & Setuju \\
\hline 11 & B2 & 77.78 & Setuju \\
\hline 12 & B3 & 80.00 & Setuju \\
\hline 13 & B4 & 77.78 & Setuju \\
\hline 14 & B5 & 63.33 & Setuju \\
\hline 15 & B6 & 77.78 & Setuju \\
\hline 16 & B7 & 77.78 & Setuju \\
\hline $\mathrm{C}$ & \multicolumn{3}{|c|}{ Faktor Kondisi Kerja } \\
\hline 17 & $\mathrm{C} 1$ & 76.67 & Setuju \\
\hline 18 & $\mathrm{C} 2$ & 62.22 & Setuju \\
\hline 19 & $\mathrm{C} 3$ & 84.44 & Sangat Setuju \\
\hline 20 & $\mathrm{C} 4$ & 66.67 & Setuju \\
\hline 21 & $\mathrm{C} 5$ & 65.56 & Setuju \\
\hline 22 & C6 & 77.78 & Setuju \\
\hline 23 & $\mathrm{C} 7$ & 73.33 & Setuju \\
\hline 24 & $\mathrm{C} 8$ & 75.56 & Setuju \\
\hline
\end{tabular}




\begin{tabular}{|c|c|c|c|}
\hline No & Pertanyaan & $\begin{array}{c}\text { Persentase } \\
(\%)\end{array}$ & Kategori \\
\hline A & \multicolumn{3}{|c|}{ Faktor Manusia } \\
\hline 25 & C9 & 66.67 & Setuju \\
\hline 26 & C10 & 70.00 & Setuju \\
\hline 27 & C11 & 71.11 & Setuju \\
\hline
\end{tabular}

Sumber : Olahan Penulis (2017)

Hasil kuesioner dari Tim Kontraktor, rata-rata responden menjawab "setuju" sebanyak 72\% dengan indikator dominan penyebab kecelakaan kerja pada pada pembangunan proyek Taman Anggrek Residence, Jakarta Barat adalah dari faktor manusia dengan indikator A.3 sebesar $95.56 \%$ yaitu tingkah laku dan kebiasaan yang ceroboh.

\section{Tim Pengawas/Owner}

Hasil jawaban kuesioner dari tim Pengawas/Owner dapat dilihat dari tabel dibawah ini :

Tabel 3. Hasil Jawaban Kuesioner Berdasarkan Kriteria Pertanyaan

\begin{tabular}{|c|c|c|c|}
\hline No & Pertanyaan & $\begin{array}{c}\text { Persentase } \\
(\%)\end{array}$ & Kategori \\
\hline $\mathbf{A}$ & \multicolumn{3}{|c|}{ Faktor Manusia } \\
\hline 1 & A1 & 75.00 & Setuju \\
\hline 2 & A2 & 77.50 & Setuju \\
\hline 3 & A3 & 90.00 & Sangat Setuju \\
\hline 4 & A4 & 80.00 & Setuju \\
\hline 5 & A5 & 85.00 & Sangat Setuju \\
\hline 6 & A6 & 70.00 & Setuju \\
\hline 7 & A7 & 77.50 & Setuju \\
\hline 8 & A8 & 82.50 & Sangat Setuju \\
\hline 9 & A9 & 67.50 & Setuju \\
\hline B & \multicolumn{3}{|c|}{ Faktor Alat-Alat Kerja } \\
\hline 10 & B1 & 47.50 & Ragu-ragu \\
\hline 11 & B2 & 85.00 & Sangat Setuju \\
\hline 12 & B3 & 67.50 & Setuju \\
\hline 13 & B4 & 65.00 & Setuju \\
\hline 14 & B5 & 57.50 & Ragu-ragu \\
\hline 15 & B6 & 77.50 & Setuju \\
\hline 16 & B7 & 90.00 & Sangat Setuju \\
\hline $\mathrm{C}$ & \multicolumn{3}{|c|}{ Faktor Kondisi Kerja } \\
\hline 17 & $\mathrm{C} 1$ & 70.00 & Setuju \\
\hline 18 & $\mathrm{C} 2$ & 62.50 & Setuju \\
\hline 19 & $\mathrm{C} 3$ & 75.00 & Setuju \\
\hline 20 & $\mathrm{C} 4$ & 72.50 & Setuju \\
\hline 21 & $\mathrm{C} 5$ & 62.50 & Setuju \\
\hline 22 & C6 & 70.00 & Setuju \\
\hline 23 & C7 & 62.50 & Setuju \\
\hline 24 & $\mathrm{C} 8$ & 75.00 & Setuju \\
\hline 25 & C9 & 67.50 & Setuju \\
\hline 26 & $\mathrm{C} 10$ & 75.00 & Setuju \\
\hline 27 & $\mathrm{C} 11$ & 75.00 & Setuju \\
\hline
\end{tabular}

Sumber : Olahan Penulis (2017)

Hasil kuesioner dari Tim Pengwas/Owner, rata-rata responden menjawab "setuju" sebanyak
$63 \%$ dengan indikator dominan penyebab kecelakaan kerja pada pada pembangunan proyek Taman Anggrek Residence, Jakarta Barat adalah dari faktor manusia dengan indikator A.3 sebesar $90.00 \%$ yaitu tingkah laku dan kebiasaan yang ceroboh dan faktor alat-alat kerja dengan indikator B.7 sebesar $90.00 \%$ yaitu pemeliharaan, serta inspeksi terhadap peralatan yang buruk.

\section{Tim Konsultan}

Hasil jawaban kuesioner dari tim konsultan dapat dilihat dari tabel dibawah ini :

Tabel 4. Hasil Jawaban Kuesioner Berdasarkan Kriteria Pertanyaan

\begin{tabular}{|c|c|c|c|}
\hline No & Pertanyaan & $\begin{array}{c}\text { Persentase } \\
(\%)\end{array}$ & Kategori \\
\hline $\mathbf{A}$ & \multicolumn{3}{|c|}{ Faktor Manusia } \\
\hline 1 & A1 & 70.00 & Setuju \\
\hline 2 & $\mathrm{~A} 2$ & 77.14 & Setuju \\
\hline 3 & A3 & 94.29 & Sangat Setuju \\
\hline 4 & A4 & 68.57 & Setuju \\
\hline 5 & A5 & 77.14 & Setuju \\
\hline 6 & A6 & 82.86 & Sangat Setuju \\
\hline 7 & A7 & 88.57 & Sangat Setuju \\
\hline 8 & A8 & 82.56 & Sangat Setuju \\
\hline 9 & A9 & 80.00 & Setuju \\
\hline B & \multicolumn{3}{|c|}{ Faktor Alat-Alat Kerja } \\
\hline 10 & B1 & 54.29 & Ragu-ragu \\
\hline 11 & $\mathrm{~B} 2$ & 94.29 & Sangat Setuju \\
\hline 12 & B3 & 80.00 & Setuju \\
\hline 13 & B4 & 82.86 & Sangat Setuju \\
\hline 14 & B5 & 65.71 & Setuju \\
\hline 15 & B6 & 82.86 & Sangat Setuju \\
\hline 16 & B7 & 85.71 & Sangat Setuju \\
\hline $\mathrm{C}$ & \multicolumn{3}{|c|}{ Faktor Kondisi Kerja } \\
\hline 17 & $\mathrm{C} 1$ & 85.71 & Sangat Setuju \\
\hline 18 & $\mathrm{C} 2$ & 54.29 & Ragu-ragu \\
\hline 19 & $\mathrm{C} 3$ & 94.29 & Sangat Setuju \\
\hline 20 & $\mathrm{C} 4$ & 85.71 & Sangat Setuju \\
\hline 21 & $\mathrm{C} 5$ & 74.29 & Setuju \\
\hline 22 & C6 & 88.57 & Sangat Setuju \\
\hline 23 & $\mathrm{C} 7$ & 77.14 & Setuju \\
\hline 24 & $\mathrm{C} 8$ & 88.57 & Sangat Setuju \\
\hline 25 & C9 & 65.71 & Setuju \\
\hline 26 & $\mathrm{C} 10$ & 80.00 & Setuju \\
\hline 27 & $\mathrm{C} 11$ & 74.29 & Setuju \\
\hline
\end{tabular}

Sumber : Olahan Penulis (2017)

Hasil Jawaban kuesioner dari Tim Konsultan, rata-rata responden menjawab "setuju" sebanyak $57 \%$ dengan indikator dominan penyebab kecelakaan kerja pada pada pembangunan proyek Taman Anggrek Residence, Jakarta Barat adalah dari faktor manusia dengan indikator A.3 sebesar 94.29\% yaitu tingkah laku dan kebiasaan yang ceroboh, faktor alat-alat kerja dengan indikator B.2 sebesar $94.29 \%$ yaitu alat yang ada sudah tidak laik 
lagi dan faktor kondisi kerja dengan indikator C.3 sebesar $94.29 \%$ yaitu cara kerja yang kurang disiplin.

\section{Tim Direct Contractor (DC)}

Hasil jawaban kuesioner dari tim direct contractor (DC) sebagai berikut :

Tabel 5. Hasil Jawaban Kuesioner Berdasarkan Kriteria Pertanyaan

\begin{tabular}{|c|c|c|c|}
\hline No & Pertanyaan & $\begin{array}{c}\text { Persentase } \\
(\%)\end{array}$ & Kategori \\
\hline $\mathbf{A}$ & \multicolumn{3}{|c|}{ Faktor Manusia } \\
\hline 1 & A1 & 82.00 & Sangat Setuju \\
\hline 2 & $\mathrm{~A} 2$ & 80.00 & Setuju \\
\hline 3 & A3 & 90.00 & Sangat Setuju \\
\hline 4 & A4 & 80.00 & Setuju \\
\hline 5 & A5 & 76.00 & Setuju \\
\hline 6 & A6 & 78.00 & Setuju \\
\hline 7 & A7 & 94.00 & Sangat Setuju \\
\hline 8 & A8 & 76.00 & Setuju \\
\hline 9 & A9 & 76.00 & Setuju \\
\hline B & \multicolumn{3}{|c|}{ Faktor Alat-Alat Kerja } \\
\hline 10 & B1 & 58.00 & Ragu-ragu \\
\hline 11 & B2 & 84.00 & Sangat Setuju \\
\hline 12 & B3 & 80.00 & Setuju \\
\hline 13 & B4 & 80.00 & Setuju \\
\hline 14 & B5 & 66.00 & Setuju \\
\hline 15 & B6 & 90.00 & Sangat Setuju \\
\hline 16 & B7 & 92.00 & Sangat Setuju \\
\hline $\mathbf{C}$ & \multicolumn{3}{|c|}{ Faktor Kondisi Kerja } \\
\hline 17 & $\mathrm{C} 1$ & 86.00 & Sangat Setuju \\
\hline 18 & $\mathrm{C} 2$ & 66.00 & Setuju \\
\hline 19 & C3 & 86.00 & Sangat Setuju \\
\hline 20 & $\mathrm{C} 4$ & 74.00 & Setuju \\
\hline 21 & $\mathrm{C} 5$ & 82.00 & Sangat Setuju \\
\hline 22 & C6 & 82.00 & Sangat Setuju \\
\hline 23 & $\mathrm{C} 7$ & 84.00 & Sangat Setuju \\
\hline 24 & $\mathrm{C} 8$ & 78.00 & Setuju \\
\hline 25 & C9 & 74.00 & Setuju \\
\hline 26 & $\mathrm{C} 10$ & 82.00 & Sangat Setuju \\
\hline 27 & C11 & 80.00 & Setuju \\
\hline
\end{tabular}

Sumber : Olahan Penulis (2017)

Hasil Jawaban kuesioner dari Tim Konsultan, rata-rata responden menjawab "Sangat setuju" sebanyak $60 \%$ dengan indikator dominan penyebab kecelakaan kerja pada pada pembangunan proyek Taman Anggrek Residence, Jakarta Barat adalah dari faktor manusia dengan indikator A.7 sebesar 94\% yaitu kurang disiplinnya para tenaga kerja dalam mematuhi ketentuan mengenai K3 yang antara lain pemakaian alat pelindung diri kecelakaan kerja.

\section{Hasil Kuesioner}

Berdasarkan analisis dari kuesioner, hasil jawaban kuesioner dapat dilihat dari tabel dibawah ini :

\section{Tim Kontraktor}

Beberapa reponden dari tim kontraktor sebanyak 18 orang, responden terbanyak menjawab "setuju" berjumlah 13 orang (72\%), hal ini dikarenakan hal-hal sebagai berikut :

a. Kebijakan K3 dalam PP Nomor 5 Tahun 2012 sudah ada, tetapi belum terlaksana dengan baik

b. Dokumentasi belum ada

c. Implementasi K3 belum terlaksana dilapangan Dari 27 indikator penyebab kecelakaan kerja pada pembangunan proyek Taman Anggrek Residence, Jakarta Barat, didapatkan indikator dominan penyebab kecelakaan kerja adalah dari faktor manusia dengan indikator A.3 sebesar 95.56\% yaitu tingkah laku dan kebiasaan yang ceroboh. Dengan indikator dominan tersebut sehingga didapatkan beberapa hasil mitigasi risiko untuk mengurangi tingkat kecelakaan kerja pada pembangunan proyek Taman Anggrek Residence, Jakarta Barat sebagai berikut :

a. Memberikan teguran bagi yang melakukan kesalahan

b. Memberikan sanksi bagi yang melakukan kesalahan

c. Memberikan surat peringatan yang sudah melakukan kesalahan berkali-kali

d. Memberhentikan kepada tenaga kerja yang melakukan kesalahan, yang sebelumnya sudah ada peringatan dan teguran

\section{Tim Pengawas/Owner}

Beberapa reponden dari tim pengawas/owner sebanyak 8 orang, responden terbanyak menjawab "setuju" berjumlah 5 orang (63\%), hal ini dikarenakan hal-hal sebagai berikut :

a. Kebijakan K3 dalam PP Nomor 5 Tahun 2012 sudah ada, tetapi belum terlaksana dengan baik

b. Dokumentasi belum ada

c. Implementasi K3 belum terlaksana dilapangan Dari 27 indikator penyebab kecelakaan kerja pada pembangunan proyek Taman Anggrek Residence, Jakarta Barat, didapatkan 2 indikator dominan penyebab kecelakaan kerja. Dengan adanya 2 indikator dominan tersebut sehingga didapatkan beberapa hasil mitigasi risiko untuk mengurangi tingkat kecelakaan kerja pada pembangunan proyek Taman Anggrek Residence, Jakarta Barat sebagai berikut :

1. Faktor manusia dengan indikator A.3 sebesar $90.00 \%$ yaitu tingkah laku dan kebiasaan yang ceroboh

a. Memberikan teguran bagi yang melakukan kesalahan

b. Memberikan sanksi bagi yang melakukan kesalahan

c. Memberikan surat peringatan yang sudah melakukan kesalahan berkali-kali 
d. Memberhentikan kepada tenaga kerja yang melakukan kesalahan, yang sebelumnya sudah ada peringatan dan teguran

2. Faktor alat-alat kerja dengan indikator B.7 sebesar $90.00 \%$ yaitu pemeliharaan, serta inspeksi terhadap peralatan yang buruk

a. Melakukan perawatan dan pengujian peralatan secara berkala

b. Mengadakan supervisi pelatan

c. Pengecekan peralatan ketika akan digunakan

d. Melakukan instruksi kerja penggunaan alat

\section{Tim Konsultan}

Beberapa reponden dari tim kontraktor sebanyak 7 orang, responden terbanyak menjawab "setuju" berjumlah 4 orang $(57 \%)$, hal ini dikarenakan hal-hal sebagai berikut :

a. Kebijakan K3 dalam PP Nomor 5 Tahun 2012 sudah ada, tetapi belum terlaksana dengan baik

b. Dokumentasi belum ada

c. Implementasi K3 belum terlaksana dilapangan Dari 27 indikator penyebab kecelakaan kerja pada pembangunan proyek Taman Anggrek Residence, Jakarta Barat, didapatkan 3 indikator dominan penyebab kecelakaan kerja. Dengan adanya 3 indikator dominan tersebut sehingga didapatkan beberapa hasil mitigasi risiko untuk mengurangi tingkat kecelakaan kerja pada pembangunan proyek Taman Anggrek Residence, Jakarta Barat sebagai berikut :

1. Faktor manusia dengan indikator $\mathbf{A . 3}$ sebesar $94.29 \%$ yaitu tingkah laku dan kebiasaan yang ceroboh

a. Memberikan teguran bagi yang melakukan kesalahan

b. Memberikan sanksi bagi yang melakukan kesalahan

c. Memberikan surat peringatan yang sudah melakukan kesalahan berkali-kali

d. Memberhentikan kepada tenaga kerja yang melakukan kesalahan, yang sebelumnya sudah ada peringatan dan teguran

2. Faktor alat-alat kerja dengan indikator B.2 sebesar $94.29 \%$ yaitu alat yang ada sudah tidak laik lagi

a. Pemilihan sistem dan peralatan yang layak

b. Mengeluarkan peralatan yang sudah tidak laik lagi

c. Pengecekan peralatan secara berkala

d. Mengganti peralatan yang sudah tidak layak digunakan

3. Faktor kondisi kerja dengan indikator C.3 sebesar $94.29 \%$ yaitu cara kerja yang kurang disiplin

a. Melakukan rapat koordinasi secara rutin
b. Membuat rencana safety patrol
c. Menentukan prosedur kerja
d. Melakukan supervisi pekerjaan

\section{Tim Direct Contractor (DC)}

Beberapa reponden dari tim direct contractor (DC) sebanyak 10 orang, responden terbanyak menjawab "setuju" berjumlah 6 orang $(60 \%)$, hal ini dikarenakan hal-hal sebagai berikut :

a. Kebijakan K3 dalam PP Nomor 5 Tahun 2012 sudah ada, tetapi belum terlaksana dengan baik

b. Dokumentasi belum ada

c. Implementasi K3 belum terlaksana dilapangan

Dari 27 indikator penyebab kecelakaan kerja pada pembangunan proyek Taman Anggrek Residence, Jakarta Barat, didapatkan indikator dominan penyebab kecelakaan kerja adalah dari faktor manusia dengan indikator A.7 sebesar 94.00\% yaitu kurang disiplinnya para tenaga kerja dalam mematuhi ketentuan mengenai K3 yang antara lain pemakaian alat pelindung diri kecelakaan kerja. Dengan indikator dominan tersebut sehingga didapatkan beberapa hasil mitigasi risiko untuk mengurangi tingkat kecelakaan kerja pada pembangunan proyek Taman Anggrek Residence, Jakarta Barat sebagai berikut :

a. Memberikan sanksi bagi yang melakukan pelanggaran

b. Pembinaan motivasi agar tenaga kerja bersikap dan bertindak sesuai dengan keperluan perusahaan

c. Pengarahan instruksi dan informasi yang lengkap dan jelas

d. Dikeluarkan dari lingkungan proyek

\section{Kesimpulan}

Dari hasil analisis evaluasi penyebab kecelakaan kerja pada pembangunan proyek Taman Anggrek Residence, Jakarta Barat dapat disimpulkan sebagai berikut :

1. Berdasarkan hasil validasi pakar, didapatkan 27 indikator penyebab terjadinya kecelakaan kerja pada Pembangunan Proyek Konstruksi Taman Anggrek Residence, Jakarta Barat.

2. Berdasarkan analisis hasil jawaban kuesioner per masing-masing tim dengan analisis keseluruhan tim, terdapat indikator dominan yang sama pada tim kontraktor, tim pengawas/owner, dan tim konsultan yaitu indikator A.3. Jadi dapat disimpulkan bahwa indikator dominan penyebab kecelakaan kerja pada pembangunan proyek Taman Anggrek Residence, Jakarta Barat, adalah dari faktor manusia dengan indikator A.3 sebesar $95.56 \%$ yaitu tingkah laku dan kebiasaan yang ceroboh. Dengan indikator dominan tersebut sehingga didapatkan beberapa hasil mitigasi risiko untuk mengurangi tingkat kecelakaan 
kerja pada pembangunan proyek Taman Anggrek Residence, Jakarta Barat sebagai berikut :

a. Memberikan teguran bagi yang melakukan kesalahan

b. Memberikan sanksi bagi yang melakukan kesalahan

c. Memberikan surat peringatan yang sudah melakukan kesalahan berkali-kali

d. Memberhentikan kepada tenaga kerja yang melakukan kesalahan, yang sebelumnya sudah ada peringatan dan teguran

\section{Daftar Pustaka}

[1] Kepmenaker Nomor 386, 2014. Petunjuk Pelaksanaan Bulan Keselamatan dan Kesehatan Kerja Nasional Tahun 2015-2019

[2] Suparyadi, 2015. Manajemen Sumber Daya Manuaia Menciptakan Keunngulan Bersaing Berbasis Kompetensi SDM. Penerbit Andi, Yogyakarta

[3] Imam Soeharto, 1995. Manajemen Proyek. Penerbit Erlangga, Jakarta

[4] Permenkes Nomor 48, 2016. Standar Keselamatan dan Kesehatan Kerja Perkantoran

[5] OHSAS 18001, 2007, Sistem Manajemen Keselamatan dan Kesehatan Kerja

[6] Perpu Nomor 05, 2014. Pedoman Sistem Manajemen Keselamatan dan Kesehatan Kerja (SMK3) Konstruksi Bidang Pekerjaan Umum
[7] Permenaker Nomor 50, 2012. Penerapan Sistem Manajemen Keselamatan dan Kesehatan Kerja

[8] Undang-undang Nomor 1. 1970. Keselamatan Kerja

[9] Mulyadi, 2015. Manajemen Sumber Daya Manuasia (MSDM). Penerbit Andi, Yogyakarta

[10] Sugiono, 2011. Metode Penelitian Pendidikan. Penerbit Erlangga, Jakarta

[11] Bayu, Widyawati, Andyana, 2015, Jurnal Evaluasi Penerapan Keselamatan dan Kesehatan Kerja, Lingkungan, dan Mutu (K3LM) Proyek Konstruksi pada PT. Waskita Karya (Studi Kasus Pada Proyek DSDP II ICB 1)

[12] Kepmenaker Nomor 372. 2009. Petunjuk Pelaksanaan Bulan Keselamatan dan Kesehatan Kerja Nasional Tahun 2010-2014

[13] Permenaker Nomor 01. 2007. Pedoman Pemberian Penghargaan Keselamatan dan Kesehatan Kerja. 